\title{
The Past Has Ears (PHE) : XR Explorations of acoustic spaces as Cultural Heritage *
}

\author{
Brian F.G. Katz ${ }^{1[0000-0001-5118-0943]}$, Damian Murphy ${ }^{2[0000-0002-6676-9459]}$, \\ and Angelo Farina ${ }^{3[0000-0002-2551-162 X]}$ \\ 1 Sorbonne Université, CNRS, Institut Jean Le Rond d'Alembert, Lutheries - \\ Acoustique - Musique, Paris, France \\ brian.katz@sorbonne-universite.fr \\ http://www.lam.jussieu.fr/Membres/Katz/ \\ 2 University of York, Department of Electronic Engineering AudioLab, \\ Heslington, York, YO10 5DD, UK \\ damian.murphy@york.ac.uk \\ 3 University of Parma, Dept. of Engineering and Architecture, \\ Via delle Scienze 181/A, 43124 Parma, Italy \\ angelo.farina@unipr.it
}

\begin{abstract}
Hearing is one of our most pervasive senses. There is no equivalent to closing our eyes, or averting our gaze, for the ears. When we think about great architectural achievements in European history, such as ancient amphitheatres or Gothic cathedrals, their importance is strongly tied to their acoustic environment. The acoustics of a heritage site is an intangible consequence of the space's tangible construction and furnishings. Inspired by the project's namesake (Phé, for the constellation Phoenix), and the relatively recent fires at Cathédrale de Notre Dame de Paris and Teatro La Fenice opera hall, the PHE project focuses on virtual reconstruction of heritage sites, bringing them back from the ashes. In addressing the intangible acoustic heritage of architectural sites, three main objectives have been identified for this research project: Documentation, Modelling, and Presentation. In parallel, three heritage sites are participating as case studies: Tindari Theatre (IT), Notre-Dame de Paris Cathedral (FR), and The Houses of Parliament (UK). The acoustics of a space is immersive, spatial, and due to the nature of auditory perception egocentric, in contrast to visual perception of an object, which can be observed from "outside". Consequently, presentation methods for communicating acoustic heritage must represent the spatially immersive and listener-centric nature of acoustics. PHE will lead development of a museum grade hardware/software prototype for the presentation of immersive audio experiences adaptable to multiple platforms, from off-site immersive speaker installations, to mobile XR via smartphone applications.
\end{abstract}

Keywords: Archaeoacoustics - Digital heritage reconstructions · Audible virtual and augmented reality · Acoustic heritage · Methodology guidelines.

* Supported by EU JPI on Cultural Heritage (JPI-CH). 


\section{Introduction}

With the recent adoption of UNESCO resolution "The importance of sound in today's world: promoting best practices", complementing the UNESCO Convention for the Safeguarding of the Intangible Cultural Heritage [12], we are now entering a new era where the acoustic soundscape of places both existing and historical merit reflection, preservation, and scientific study.

Preserving acoustics of historical buildings and concert halls for the posterity had been the dream of Michael Gerzon back in the seventies [6], and was first made possible by measuring multichannel impulse responses in 2003 [5].

When we think about great architectural achievements in European history, such as ancient amphitheatres or Gothic cathedrals, their importance is strongly tied to their acoustic environment. The acoustics of a heritage site is an intangible consequence of the space's tangible construction and furnishings. It is ephemeral, while also a concrete result of the physical nature of the environment. Through the "Past Has Ears" project (the PHE project ${ }^{4}$ ), we will explore how via measurements, research, and virtual reconstructions the acoustics of heritage spaces can be documented, reconstructed, and experienced for spaces both existing and in various altered states.

Inspired by the project's namesake (Phé, for the constellation Phoenix), and the relatively recent fires at Cathédrale de Notre Dame de Paris (2019) and Teatro La Fenice opera hall [20] (1996, Fenice also meaning Phoenix), the PHE project focuses on the preservation, conservation, and reconstruction of heritage sites, bringing them back from the ashes for use by researchers, stake holders, cultural institutions, and the general public.

\section{Overview}

Comprising research teams with experience in acoustic reconstructions and historical research, paired with national heritage monuments of acoustic importance, the consortium will develop a joint methodology for addressing relevant archaeological acoustics issues across Europe with historians of different disciplines. Specialists in tangible/intangible cultural heritage legal issues ensure the viability and longevity of the methodology guidelines. The consortium will prototype next generation exploration tools for presenting digital acoustic reconstructions to scientists and museum visitors alike. Results will be evaluated with associated test heritage sites, created in partnership with stakeholders and experienced content producers. Presentation methods provide first-person in-situ or off-site explorations, with the ability to experience various historical periods. For deteriorated sites, this approach provides access to situations impossible to experience on-site. Additional uses include participative experiences, employing real-time reconstructions for on-site concerts and other events experienced in the heritage acoustics.

\footnotetext{
4 https://evaa.lam.jussieu.fr/doku.php\#phenixthe_past_has_ears
} 
Responding to the EU Joint Programming Initiative on Cultural Heritage (JPI-CH) Conservation, Protection and Use joint CFP (2019), PHE addresses the challenges of "Layered conservation", "Sustainable protection and enhancement of values", and "Management of cultural heritage at risk". The project's goal is developing new methods for presenting acoustic heritage to both researchers and users, raising awareness and adding value to what is currently intangible heritage. This is achieved through development of a museum grade hardware/software prototype for the presentation of immersive audio experiences adaptable to multiple platforms, from off-site immersive speaker installations, to mobile AA/VR (XR) via smartphone applications.

Three principal objectives have been identified concerning the project: Documentation, Modelling, and Presentation. These research concepts are directed towards three case studies, adjusting to the unique requirements of each site. The overlying goal being the formulation of techniques, tools, and a system prototype that is adaptable to various site conditions and test cases, providing a flexible yet realistic immersive audio rendering of historic states of cultural heritage buildings. It is intended that the results of such a project will facilitate increased acceptance and integration of acoustic aspects within heritage research and communication with the public.

This paper presents an overview of the current project and the principal elements of XR related research. Modelling and Presentation directly concern $\mathrm{XR}$ on the three sites, and are therefor exposed in more detail here. Such research builds on previous results and knowledge previously acquired in the development and use of virtual acoustics and room acoustic simulations.

\section{Principal objectives of the project}

\subsection{Documentation: Acoustical, Archaeological, Architectural, and Cultural}

Any conservation-restoration process of a heritage site requires gathering documentation, scientific investigations, and a detailed state of repair, which form the basis for the elaboration of a diagnosis and subsequent project. Documentation of acoustics of historic sites is still an emerging notion in various associated fields, with no standards of practice or generally accepted methodologies.

PHE will develop a framework protocol for digital documentation through precise measurements of acoustic states of a site that is sufficient for providing a safeguarded reference in the event of evolution of the site, or in the event of disaster. Like the Theatro La Fenice and hopefully for the Cathédral de Notre Dame de Paris, such heritage sites can emerge from the flames of disaster with their acoustics preserved, being an integral part of their historic value. An open public database will be constructed consisting of descriptions, associated acoustic property characterisations and measurements, and in-situ recordings when possible to foster an accepted reference for discussion and exchange among researchers across Europe in the different domains. Such a database shall improve 
the quality of historical acoustic simulations, but providing much needed data on acoustic and physical properties of materials rarely used today in modern constructions, and therefore poorly documented.

\subsection{Modelling: From Evidence to Auralisation, Layered history modelling and simulations}

Physical and digital reconstruction methods have been used in acoustics for decades. However, it is only relatively recently that evolutions in computational technologies have opened the doors to improved quality and resolution of acoustic modelling for large-scale spaces where acoustics is crucial and spaces are increasingly complicated. Recent efforts in calibration techniques have shown that properly simulated spaces can be perceptually comparable to actual on-site spatial recordings [16 17]. Once created, these models are modified to explore alternative states, testing acoustic conditions under various architectural or decorative configurations, source and listener positions, use contexts, etc. As a tool, acoustic simulations provide a new and powerful resource for historical studies, providing researchers a sensorial presentation of heretofore-textural descriptions [8]11 15.

The "transparent" nature of acoustics provides ideal conditions for studying the layered nature of history within architectural sites. With a geometrically accurate 3D model, incorporating acoustic properties of materials and construction, accurate predictions are made of the evolution in the acoustics as a function of changes in different material's history. Changes occurring through the introduction, modification, or removal of significant elements as well as degradation over time or major catastrophes are incorporated based on accurate documentation and informed extrapolation through archaeological evidence. Changes in use are examined, focusing on the evolution of a site in relation to the evolution of culture and customs over time and the associated actions of our predecessors to adjust their acoustic environment to accommodate their needs.

As evidenced by prior works [12]13/18,19, there are varieties of methods available to carry out such simulations. Such variety of choice implies an equal variety in modelling parameters and results. With the aim of providing common research environments in acoustic heritage, it is necessary to work towards a uniform model definition methodology, independent of the tools employed, while providing an assessment of different approaches available.

An evaluation of current state-of-the-art and under development modelling methods will be carried out, examining for example ray-tracing, digital waveguides, image-source method, finite-difference time domain (FDTD), and stochastic processing approaches which have all been shown to hold hold some promise which each exhibit certain limitations. The quality of resulting simulations are evaluated regarding authenticity from metric analysis perspectives and human perception perspectives, as listening to digital reconstructions is often more meaningful as a means to study acoustic heritage and to communicate its cultural nature, raising awareness for non-specialists [914. 


\subsection{Presentation/Use of heritage acoustics}

The acoustics of a space is immersive, spatial, and due to the nature of auditory perception egocentric (first-person reference frame, individual), in contrast to visual perception of an object, which can be observed from "outside" (e.g. bird's eye view), or where the observation position does not seriously affect the information conveyed. Consequently, presentation methods for communicating acoustic heritage must represent the spatially immersive and listener-centric nature of acoustics. "Auralization" is the sound equivalent of visualization for the results of modelling techniques. The auditory presentation of accurate acoustical numerical models, through auralization over headphones or speaker arrays, allows users to experience spatial acoustic properties of a site as if present $3 / 4 / 7 / 10 / 16$.

Due to the intangible nature of acoustics, and reactive nature of room acoustics, in that it does not "sound" on its own, requiring a sound source to be heard, the choice of sound material, and its presentation, have significant impacts on information transmission to users when attempting to provide a relevant and meaningful experience. Choice of source material are highly pertinent in raising awareness and integrating acoustic heritage in its cultural and societal context. The connection of heritage sites to their surroundings, through soundscape analysis and reconstruction, provides further means for communicating the temporal and cultural context, raising awareness of heritage's importance as a whole.

Different means for presenting acoustic heritage have been employed in recent years, with each production often being limited to the presentation system employed. While developments for off-site presentation have been more prevalent, in-situ rendering of immersive acoustic heritage has not advanced beyond the traditional "audio-guide", with its associated limitations. PHE will lead development of a museum grade hardware/software prototype for the presentation of immersive audio experiences adaptable to multiple platforms, from off-site immersive speaker installations, to mobile XR via smartphone applications.

On-site XR presentation will focus primarily on spatial audio rendering, using hear-through headphones. This direction allows for the actual visual state of a heritage site to be combined with a spatially coherent immersive auditory scene. Platform agnostic spatial audio formats (e.g. Higher-Order Ambisonics) will be used to minimize the impact of rendering in multiple user scenarios. Tracking will be integrated in the headphone device while a comparable smartphone application may use the orientation sensors available and standard headphones for a lower-quality but still immersive experience. Off-site presentation will focus on the use of speaker-array installations, which can be combined with image projection, for multiple users or off-the-shelf VR headsets.

Various degrees of interaction are possible, depending on the presentation platform. In addition to the ability to move about in the space, the user will be able to adjust their time-window perspective through history, experiencing the layered history. Focus can be applied to different elements or event. Further interaction with the acoustics of the virtual space is also possible, given available computing power, allowing the user for example to experience their own voice on stage in the former theatre in front of a full audience. 


\section{Cultural heritage site case studies}

The project explores how through measurements, research, and finally virtual reconstructions the acoustics of heritage spaces can be documented, reconstructed, and experienced. Spanning a variety of heritage site conditions, three case studies with prominent heritage sites where acoustics plays a major role will be used to examine how to address the conservation, protection, and use of spaces both past and present. The case study sites represent public sites of importance in the form of an ancient Greek theatre (far from its original condition), a Gothic Cathedral (in the midst of recovering from a serious catastrophe, inaccessible to the public for some years), and the House of Commons (limited accessibility to the public, of significant cultural and political importance, and a key site for future preservation).

Notre-Dame de Paris: As soon as it was built at the end of the XII ${ }^{\text {th }}$ c., the Gothic cathedral of Notre-Dame de Paris became the emblematic place of musical creation in Europe. For more than 850 years, Notre-Dame de Paris has been the sounding box for the city's sacred music. Built to amplify the sacred word spoken or sung, the Cathedral is a multiform sound space where the clamor of the pilgrims circulating in the ambulatory and the chanting of the services protected by the choir's enclosure, the soloist singing the mass and the humming of the low masses in the radiant chapels, used to coexist until today, when before the fire, the call to silence for noisy visitors, the sound of the masses, the bursts of sound from the great organs and the concerts alternated.

House of Commons: This work builds upon the Listening to the Commons project, where the goal was to develop a first-stage acoustic model of pre-1834 UK House of Commons Chamber and the roof-void above, where women, who were otherwise excluded from this space, gathered to access and engage with political debate via listening through a ventilator. Measured acoustic data has also been gathered from the current House of Commons Chamber, and other historic sites in the UK comparable in design and period to to the pre-1834 Chamber. The Commons chamber itself houses of one of the world's first parliamentary democracies.

Theater of Tindari: This ancient building erected at the end of the IV ${ }^{\text {th }} \mathrm{BC}$, was renovated, and transformed during the Roman period, then abandoned during the Late antique period. Research on the possible use of the space will help understand its fate until the $\mathrm{XX}^{\text {th }}$ c. With a capacity of $\approx 3000$, it was used continuously until the Roman imperial age before undergoing substantial modifications, accommodating gladiatorial and animal combat. Today, it hosts musical and theatrical events. 


\section{Conclusion}

The transparent and ephemeral nature of acoustics facilitates understanding of temporalities of acoustic heritage, whereby layers of cultural meaning and temporal history of materials and constructions are analysed by researchers, conveyed to interested users and the community as a whole. Combining methodical and generalized documentation procedures with validated digital modelling and simulation methods to ensure both physical and historic authenticity, the development and use of new digital tools and methods focusing on the emerging impact of auditory-VR/AR will foster new understandings and interpretations of sites and associated events. In proposing a temporally layered presentation, previous, present, and future interpretations are updated according to results of current and future historical research and discoveries.

\section{Acknowledgements}

Funding has been provided by the JPI-CH project PHE.

\section{References}

1. The importance of sound in today's world: promoting best practices. Tech. Rep. Resolution 39 C/49, UNESCO (2017), https://unesdoc.unesco.org/ark: /48223/pf0000259172

2. Convention for the safeguarding of the intangible cultural heritage. Tech. rep., UNESCO (2018), https://ich.unesco.org/en/convention

3. Capra, A., Binelli, M., Marmiroli, D., Martignon, P., Farina, A.: Correlation between subjective descriptors and objective parameters of theatres and auditoria acoustics simulated with binaural sound systems. In: Intl Cong Sound and Vibration. pp. 1-8 (2006)

4. Farina, A.: Acoustic quality of theatres: correlations between experimental measures and subjective evaluations. Applied Acoustics 62(8), 889 - 916 (2001). https://doi.org/https://doi.org/10.1016/S0003-682X(00)00082-7

5. Farina, A., Ayalon, R.: Recording concert hall acoustics for posterity. In: Audio Eng Soc Conf. vol. Multichannel Audio, The New Reality (Jun 2003), http:// www. aes.org/e-lib/browse. cfm?elib=12277

6. Gerzon, M.A.: Recording concert hall acoustics for posterity. J Audio Eng Soc 23(7), 569-571 (1975), http://www.aes.org/e-lib/browse.cfm?elib=2669

7. Harriet, S., Murphy, D.T.: Auralisation of an urban soundscape. Acta Acustica united with Acustica 101(4), 798-810 (2015). https://doi.org/doi:10.3813/AAA.918874

8. Katz, B.F.G., Mervant-Roux, M.M.: Comment entendre le passé ? Quelques leçons d'une collaboration de recherche entre acousticiens et spécialistes d'études théâtrales. Revue Sciences/Lettres SI: L'Écho du théâtre(6), 1-14 (2019). https://doi.org/10.4000/rsl.1645, English title: How to hear the past? Some lessons from a collaborative research between acousticians and theatre studies specialists

9. Lovedee-Turner, M., Murphy, D.: Application of machine learning for the spatial analysis of binaural room impulse responses. Applied Sciences 8(1), 105 (Jan 2018). https://doi.org/10.3390/app8010105 
10. Marco Binelli, Daniel Pinardi, T.N., Farina, A.: Individualized HRTF for playing VR videos with Ambisonics spatial audio on HMDs. In: Audio Eng Soc Conf. vol. AVAR, pp. 1-10 (2018)

11. Murphy, D., Shelley, S., Foteinou, A., Brereton, J., Daffern, H.: Acoustic heritage and audio creativity: the creative application of sound in the representation, understanding and experience of past environments. Internet Archaeology 44 (2017). https://doi.org/10.11141/ia.44.12

12. Murphy, D.: Spatial audio measurement, modeling and composition. Leonardo 39(5), 464-466 (2006). https://doi.org/10.1162/leon.2006.39.5.464

13. Noisternig, M., Katz, B., Siltanen, S., Savioja, L.: Framework for real-time auralization in architectural acoustics. Acta Acust united Ac 94, 1000 -1015 (2008). https://doi.org/10.3813/AAA.918116

14. Postma, B.N., Demontis, H., Katz, B.F.: Subjective evaluation of dynamic voice directivity for auralizations. Acta Acust united Ac 103, 181-184 (2017). https://doi.org/10.3813/AAA.919045

15. Postma, B.N., Dubouilh, S., Katz, B.F.: An archeoacoustic study of the history of the Palais du Trocadero (1878-1937). J Acoust Soc Am SI: Room Acoustics Modeling and Auralization, 2810-2821 (Apr 2019). https://doi.org/10.1121/1.5095882

16. Postma, B.N., Katz, B.F.: Perceptive and objective evaluation of calibrated room acoustic simulation auralizations. J Acoust Soc Am 140(6), 4326-4337 (Dec 2016). https://doi.org/10.1121/1.4971422

17. Postma, B.N., Katz, B.F.: Creation and calibration method of virtual acoustic models for historic auralizations. Virtual Reality 19, 161-180 (2015). https://doi.org/10.1007/s10055-015-0275-3, SI: Spatial Sound

18. Southern, A., Murphy, D.T., Savioja, L.: Boundary absorption approximation in the spatial high-frequency extrapolation method for parametric room impulse response synthesis. J Acoust Soc Am 145(4), 2770-2782 (2019). https://doi.org/10.1121/1.5096162

19. Stevens, F., Murphy, D.T., Savioja, L., Välimäki, V.: Modeling sparsely reflecting outdoor acoustic scenes using the waveguide web. IEEE/ACM Transactions on Audio, Speech, and Language Processing 25(8), 1566-1578 (2017)

20. Tronchin, L., Farina, A.: Acoustics of the former teatro -la fenice- in venice. J Audio Eng Soc 45(12), 1051-1062 (1997), http://www.aes.org/e-lib/browse. cfm?elib=7834 